\title{
COZINHA TERÉNA: NOVAS PRÁTICAS ALIMENTARES EM TEMPOS DE MUDANÇA
}

EVERTON FERREIRA LEMOS ${ }^{1}$

$U F M S$

DULCE LOPES BARBOZA RIBAS ${ }^{2}$

UFMS

MARIA CRISTINA BIGNARDI PESSÔA ${ }^{3}$

UFMS

MARIA HELENA VILLAS BOAS CONCONE ${ }^{4}$

$P U C-S P$

\begin{abstract}
RESUMO: Este estudo teve por objetivo identificar aspectos da cozinha terena, analisando a composição da dieta, as práticas alimentares e recomendações gerais em situações específicas da vida, como o puerpério e presença de doenças. O estudo foi de abordagem qualitativa com indivíduos terena, identificados como informantes-chave nas questões da comida e cozinha e residentes na Terra Indígena Buriti, Mato Grosso do Sul, Brasil. Os relatos evidenciaram significativas mudanças nas práticas alimentares, com destaque para as mudanças ocorridas na obtenção e plantio dos próprios alimentos, a introdução de alimentos industrializados e as preocupações com os resultados oriundos dos novos hábitos. A limitação da área disponível, a degradação ambiental e a presença de alimentos fornecidos na cesta básica foram indicadas como elementos que contribuem para alterações da dieta terena. A permanência da cozinha de taquarussu, o fogão a lenha, a conservação das carnes pela desidratação, os alimentos disponíveis no fogão, o local das refeições, a família reunida, os utensílios e as receitas transmitidas oralmente são elementos repletos de valores simbólicos da cultura terena. Novos estudos são necessários para aprofundamento de elementos aqui identificados e abordados
\end{abstract}

\footnotetext{
${ }^{1}$ Enfermeiro, Mestre em Ciências da Saúde pela Universidade Federal da Grande Dourados (UFGD). Membro do Grupo de Estudos e Pesquisas em Populações Indígenas (GEPPI/UFMS). E-mail: tonufms@gmail.com.

${ }^{2}$ Nutricionista, Docente associada da Universidade Federal de Mato Grosso do Sul, coordenadora do Grupo de Estudos e Pesquisas em Populações Indígenas (GEPPI/UFMS), doutorado em Saúde Pública pela Universidade de São Paulo e Pós-doutorado em Antropologia da Saúde pela Pontifícia Universidade Católica de São Paulo. E-mail: dulce.ribas@ufms.br.

${ }^{3}$ Nutricionista, Mestre em Saúde e Desenvolvimento da Região do Centro Oeste. Membro do Grupo de Estudos e Pesquisas em Populações Indígenas (GEPPI/UFMS). E-mail: crisbignardip@ gmail.com.

${ }^{4}$ Cientista Social, Docente Titular do Departamento de Antropologia da Pontifícia Universidade Católica de São Paulo (PUC/SP), doutorado em Antropologia pela PUC de São Paulo. Docente e orientadora nos Programas de Pós-Graduação em Ciências Sociais (Fac. de Ciências Sociais) e em Gerontologia (Fac. Ciências Humanas e da Saúde) da PUC-SP. E-mail: trcconcone@yahoo.com.br .
}

Espaço Ameríndio, Porto Alegre, v. 8, n. 2, p. 87-107, jul./dez. 2014. 
como pequenos fragmentos da realidade, necessitando de maior discussão teórica sobre a rica experiência terena em contexto de mudança.

PALAVRAS-CHAVE: práticas alimentares; simbolismo; índios sul-americanos.

\begin{abstract}
This study aimed to identify aspects of Terena kitchen, analyzing the composition of the diet, dietary practices and general recommendations in specific life situations, such as postpartum and presence of disease. The study was a qualitative approach with Terena individuals identified as key informants, residents of the Terra Indígena Buriti in Mato Grosso do Sul, on issues of food and cooking and, Brazil. The reports showed significant changes in dietary practices, with emphasis on changes in securing and growing own food, the introduction of processed foods and concerns of results from the new habits. The limitation of the available area, environmental degradation and the presence of food provided in the basket were indicated as contributing to changes in Terena diet. The permanence of Taquarussu kitchen, the stove, the preservation of meat by dehydration, the available food on the stove, place of meals, family together, utensils and recipes passed down orally elements are full of symbolic values of Terena culture. Further studies are needed to deepen elements here identified and addressed as small fragments of reality, requiring more theoretical discussion about the Terena's rich experience in the context of change.
\end{abstract}

KEYWORDS: feeding practices; symbolism; South American indians.

\title{
Introdução
}

O comer é um ato complexo e não significa apenas a ingestão de nutrientes, mas envolve também valores culturais específicos. Há um sistema de símbolos e significados que estão associados à dimensão do comer e que precisam ser compreendidos pelos profissionais de saúde para melhor desenvolver as ações relativas às orientações ou restrições alimentares utilizadas no tratamento das doenças.

Roberto DaMatta (1986) estabelece uma distinção entre comida e alimento em que comida não é apenas uma substância alimentar, mas é também um modo, um estilo e jeito de alimentar-se, definindo não só aquilo que é ingerido como também aquele que o ingere.

Para Remem (1993), o surgimento de uma doença sempre causa uma interrupção nos costumes dos indivíduos. A escolha das representações sociais como referencial teórico pode possibilitar maior compreensão dos significados e dos aspectos psicossociais envolvidos nas doenças crônicas e seu tratamento.

Espaço Ameríndio, Porto Alegre, v. 8, n. 2, p. 87-107, jul./dez. 2014. 
De acordo com Canesqui (2005), se os profissionais de saúde desejam compreender como os saberes, representações e discursos fazem sentido para a ação, será sempre importante, por um lado, reportá-los às necessidades cotidianas das pessoas e, por outro, às características e aos valores do seu grupo social e às suas relações sociais.

As representações que as pessoas elaboram acerca de sua doença intervêm nas escolhas alimentares em função do tipo de tratamento que se busca, na maneira de comer e no seguimento das recomendações prescritas pelos profissionais. Assim, torna-se fundamental que os profissionais de saúde conheçam tais representações, a fim de desenvolver ações mais eficazes no controle das doenças.

De acordo com Bunchaft e Gondim (2004), na abordagem qualitativa, o enfoque está na compreensão de um contexto particular, respaldado na busca de significado, na subjetividade e na intersubjetividade.

O interesse nesta temática de investigação justifica-se pela necessidade de aprofundar o conhecimento sobre grupos indígenas, especialmente daqueles que vivem mudanças sociais com graves repercussões na saúde.

\section{Metodologia}

O estudo foi de abordagem qualitativa com indivíduos terena, residentes na Terra Indígena Buriti, Mato Grosso do Sul, Brasil.

O trabalho de campo constituiu-se numa etnografia, sendo utilizado o gravador como instrumento de registro, quando consentido pelo entrevistado, e um diário de campo, que objetivou complementar os registros no que se refere às expressões faciais, ao ambiente e a outras observações que passam despercebidas nas gravações.

Assim, a coleta de dados utilizou as seguintes técnicas de pesquisa:

- Entrevistas semiestruturadas individuais com informanteschave, com a finalidade de identificar as práticas alimentares. 
- Entrevistas semi-estruturadas com indivíduos adultos com diagnóstico de doença.

- Observação participante com o objetivo de acompanhar as práticas vivenciadas e efetivamente realizadas no cotidiano das famílias.

As entrevistas foram realizadas, em particular, nos domicílios, buscando a proximidade e a privacidade das informações.

Participaram do estudo indivíduos identificados como informantes-chave nas questões da comida e cozinha terena e indivíduos adultos com diagnóstico de doença residentes nas aldeias eleitas que aceitaram livremente participar.

O estudo está inserido nas atividades do Grupo de Estudos e Pesquisa em Populações Indígenas (GEPPI) da Universidade Federal de Mato Grosso do Sul (UFMS), e faz parte de um projeto mais amplo denominado "Nutrição, saúde e condições de vida Terena", que foi submetido ao Comitê de Ética em Pesquisa da UFMS e à Comissão Nacional de Ética em Pesquisa, assim como às lideranças indígenas da Terra Buriti e à Administração Executiva Regional e Nacional da FUNAl. Foram prestados esclarecimentos sobre o estudo no intuito de informar e possibilitar a livre decisão de participar ou não, bem como a garantia de novos esclarecimentos durante todo o período de realização. Somente após o entendimento e aceite pela comunidade, pela família e pelos indivíduos eleitos, os trabalhos tiveram início.

\section{Resultados e discussão}

Foram ouvidos 17 indivíduos com idade entre 40 e 90 anos, moradores da Terra Indígena Buriti.

O trabalho teve a preocupação de respeitar o jeito de ser terena, iniciando a coleta de dados em campo por pesquisadores devidamente treinados e que já tinham vivenciado outros trabalhos na comunidade.

O período de coleta de dados (oito meses) foi o tempo necessário para a convivência, acompanhamento de atividades e diversos acontecimentos na comunidade, como festas, casamentos e velórios.

Durante o período de coleta de dados, a única dificuldade encontrada foi com relação ao acesso ao local, em algumas viagens, 
devido às fortes chuvas na região, o que impossibilitava a travessia em um dos rios.

As entrevistas ocorreram com consentimento dos indivíduos e no interior das moradias. Durante toda a pesquisa, a receptividade bem como a espontaneidade, fizeram parte do encontro entre o pesquisado e o entrevistador.

A cordialidade terena em acolher o visitante, disponibilizar o melhor assento da casa e oferecer alimentos como chá, café, tereré (erva-mate regado com água gelada), batata doce cozida e doces fizeram parte dos encontros.

As entrevistas foram realizadas com homens e mulheres. Quando elas ocorriam com o casal, as mulheres falavam pouco e a conversa era conduzida pelo homem. Nestes casos, o homem tinha voz mais presente, e as mulheres apenas confirmavam o que o esposo relatava.

Procuramos evitar constrangimentos aos entrevistados com a utilização do gravador. O mesmo era colocado ao lado, sobre um banco ou uma mesa, o que proporcionava comodidade e respeito aos entrevistados, podendo ser rapidamente esquecido após o início do diálogo.

As narrativas colhidas foram divididas em temas observados com maior frequência, como posicionamentos e valores no que se refere à prática da alimentação terena, e apresentados nos itens seguintes.

\section{O comer}

A escolha dos alimentos e os hábitos alimentares costumam revelar as predisposições mais profundas do habitus (SLOAN, 2005).

Garcia (1993) diz que o comportamento alimentar leva às práticas alimentares, que vão desde a seleção dos alimentos e preparação até o consumo propriamente dito, incluindo valores simbólicos associados à alimentação.

Nas narrativas abaixo, são apresentados os produtos-base da alimentação cotidiana, revestidos da forma particular de preparar e consumir. 
Ah! Eu cozinho essa comida da aldeia. Lá na cidade tem o tal de prato, aqui não... Aqui nossa comida é o arroz e feijão, às vezes tem uma carninha, farofa e macarronada (D.P.).

Nós não ficamos sem o arroz. Não tendo o arroz no meio da comida, não tem comida. O arroz é em primeiro lugar. A gente gosta de comer uma carninha assada gordinha e uma mandioca. Sempre tendo, é muito bom (L.J.).

A gente cozinha arroz, feijão e mandioca, é o que a gente sempre tem. A melhor receita que eu acho é a carne com mandioca, o guisadinho (L.G.).

Os alimentos indicados caracterizam a reduzida variedade de alimentos, a disponibilidade local, o poder de compra, a existência da roça, a presença de alimentos industrializados e algumas das preferências individuais.

De preferência é o quibebe de carne, guisado. Eu gosto do guisado, quibebe de mandioca. Esse é meu predileto (B.J.).

Arroz, feijão, carne e a mandioca (A.H.).

$\mathrm{Na}$ indicação da forma de preparo e as combinações dos alimentos, destacamos os relatos dos mais idosos com a indicação da preferência por ensopados de carne e mandioca. Nos demais relatos foram citados o arroz, o feijão, a carne e a mandioca, base da alimentação terena.

Eu gosto mais de macarrão, seco assim, massa de tomate, com bastante cebola. Eu gosto quando a carne está bem temperada, às vezes, eu boto uma farinha, ou uma sopa que a gente faz, né? Com tempero certo. A gente coloca massa de tomate e cebola. Eu gosto de bastante cebola na carne quando eu faço, dá um sabor melhor. O alho, a cebola, eu coloco bastante, né? Pra ficar gostoso (M.A.).

Fischler (1995) aponta para quatro fatores que intervêm na gênese dos gostos alimentares: biológicos, psicológicos, culturais e 
sociais. Para ele, apesar da família e da educação constituir um fator fundamental na transmissão e na gênese dos gostos alimentares, a maior influência é a do meio social.

Os relatos apresentam a utilização de temperos, como a massa de tomate industrializada e a cebola no preparo dos pratos, especialmente no preparo de macarrão e em alguns pratos com carne. Em relatos dos mais idosos, eles lembram que suas mães preparavam os alimentos sem temperos, inclusive sem o sal, e que o alho, a cebola e a massa de tomate é algo que veio junto com os "brancos".

No almoço era uma mandioca com carne de bicho... tatu ou queixada, não comia sal (L.R.).

Em outro momento, o mesmo entrevistado nos contou que visitou parentes na região norte e lá foi recebido com peixe sem temperos.

O peixe não descia porque estava sem sal (L.R.).

Desta forma, mudanças influenciadas por inúmeros fatores desenvolvem uma dinâmica no conceito de gosto alimentar; o que antes era comum, ausência do sal, hoje torna-se necessidade ao paladar, o que contribuiu para adaptações ao meio ao qual este gosto está condicionado.

Em estudo realizado por Zaluar (apud ROMANELLI, 2006), para a população de baixa renda, os alimentos que sustentam são o arroz, o feijão e a carne. Em suas representações, são alimentos "fortes" e se contrapõem a verduras, legumes e frutas, que servem para "tapear" e são indicados no diminutivo como "coisinhas", "saladinhas", "verdurinhas" que não enchem barriga.

Olha! O que a gente mais gosta de comer é uma carne assada... gordinha, uma mandioca, uma verdurinha de vez em quando (L.J.).

Buscamos identificar a interpretação sobre os alimentos que são considerados fortes e fracos. Essas categorias foram apresentadas definindo a qualidade, bem como as propriedades dos alimentos.

Hoje a comida é muito fraquinha, insensível. Antigamente não. Chegava numa fazenda era uma 
panelada de pucheiro, carne, mandioca, caldo, arroz, feijão, doce à vontade. Só coisa forte. Hoje não tem mais isso. Ia no mato, derrubava uma anta, ou um cateto, uma carne de bicho... forte, todos comiam com prazer (G.C.).

De acordo com os relatos, a indicação de alimentos considerados "fortes" corresponde à comida do passado, com alto valor energético, vinda da mata, com fartura e proporcionando prazer aos comensais. A representação da comida atual é de ser "fraca", sem gosto, insuficiente e que não sustenta.

Para Canesqui (2007), estudos etnográficos mostram a preferência das camadas populares pela "comida forte", por garantir resistência e aptidão para o trabalho e proteger contra a fome, prolongando a sensação de saciedade.

Quando perguntamos sobre as mudanças na comida, em muitos relatos foi discutida a questão da industrialização dos alimentos, as novas formas de plantar com a utilização de defensivos agrícolas e o desaparecimento de alimentos tradicionais consumidos na mesa terena devido às inúmeras mudanças ao longo do tempo em suas vidas.

A "nova comida" veio carregada de incertezas e preocupações quanto ao ato de alimentar-se. Os alimentos in natura, vindos da agricultura familiar, da caça e pesca se contrapõem à presença dos industrializados, gerando insegurança frente ao desconhecido.

O alimento mudou muito, não é mais como o de antigamente. Planta um arroz ou feijão no veneno. Estamos comendo óleo de soja, praticamente criado do veneno. Ninguém come mais banha de porco e do gado, uma banha natural (G.C.).

Antigamente o arroz era da lavoura, colhido da terra, não teria tanto problema. Hoje não, deixa de plantar arroz algumas vezes, pela própria perda de lavouras, para ir ao mercado comprar (J.R.).

Joga muito veneno na lavoura, às vezes nós já comemos, já compramos uma coisa minado, né? (A.H.).

Diante das novas opções na mesa terena, os interlocutores realizaram uma ampla análise sobre aquilo que sempre fizeram: plantar 
e colher alimentos. Discutiram sobre o uso indiscriminado de defensivos agrícolas, das características atuais da área que possuem para plantar, das mudanças climáticas, dos ataques de pragas nas lavouras, o ritmo de crescimento das plantas, do recebimento de cestas básicas e da proximidade das cidades com as ofertas de alimentos industrializados.

Harmonizar da melhor forma possível os ritmos da vida com os da natureza sempre foi uma exigência primária para os Terena, garantindo a autossustentação, porém agora manifestam outras preocupações como o uso e a dependência de alimentos que desconhecem a forma como foram produzidos. O comprar alimentos e o aprender a comer exemplificam a inserção do novo e do desconhecido no regime alimentar terena.

Hoje temos que comprar açúcar... óleo de soja. Aprendemos a comer macarrão e massa de tomate. Comer comida do branco! Coisa que no passado não, plantávamos e produzíamos.

Comia coisas naturais. Não sabíamos o que era carne de frango congelado. Nós criávamos! Minha mãe criava porco e galinha... tudo natural. Não precisávamos ficar comprando açúcar, tínhamos o mel de abelha. Tínhamos frutas, peixe, caça que era abundante e hoje nem lambari a gente vê mais (B.J.).

Silva (1949) relata que, na década de 40 , os Terena combinavam a agricultura com a caça e a pesca. Eles continuam cultivando produtos vegetais para o consumo e trocas familiares, porém devido às questões de restrição e degradação de suas áreas, o plantio está cada vez mais reduzido. A caça e a pesca só ocorrem esporadicamente e fora da área reservada.

Quando nós éramos crianças, meus tios e meu pai plantavam arroz, aí a gente colhia arroz da roça e colocava pra secar no sol e socava no pilão. Socava ele bem socadinho, aí abanava pra cozinhar. Agora isso, não tem mais hoje em dia. Agora tudo é comprado, né? Nós fomos criados comendo arroz socado no pilão. $E$ era tão bom, eu sinto saudades daquele tempo (M.A.).

Meu tio plantava canavial e nós ajudávamos moer pra fazer rapadura, fazer doce. E hoje em dia não tem mais isso daí, né? Modificaram tudo as coisas agora (M.A.).

Espaço Ameríndio, Porto Alegre, v. 8, n. 2, p. 87-107, jul./dez. 2014. 
A comida do índio é mandioca, batata assada, cará, uma carne de bicho qualquer: de anta ou capivara. Mas também a gente não tem mais. Isso é comida de índio (A.S.).

Das famílias estudadas, a maioria possuía a roça, sendo para consumo próprio, trocas familiares ou, ainda, para a comercialização, gerando renda familiar. O plantio mais comum verificado entre as famílias foi de mandioca, feijão, arroz e milho. A mandioca está presente tanto na roça quanto no próprio quintal do domicílio.

As famílias relataram participar do programa assistencial do governo do estado, onde recebem cestas de alimentos mensalmente. Para algumas famílias, os alimentos recebidos são fundamentais e representam, muitas vezes, a única fonte de alimentos. Entre os componentes da cesta alimentar, estão produtos que não eram consumidos tradicionalmente ou nem mesmo adquiridos com frequência, como macarrão, extrato de tomate, leite em pó, açúcar e óleo de soja.

Nesta perspectiva de mudança e de introdução de novos produtos, investigamos os alimentos de que sentiam falta, que provocavam boas lembranças ou que estariam relacionados com a boa saúde. Os relatos indicaram a carne de caça como a comida que mais trazia lembranças e estava relacionada a "fazer bem para a saúde".

O cateto ou queixada, sabendo prepará-lo, é uma carne muito boa. Minha mãe fazia... Picava e lavava bem. Cozinhava com folha de mandioca, destampado para sair o bafo para cima, para não ficar aquele cheiro. [...] colocava bastante banha e fritava. Era outro sabor. Você comia um bicho desse falava que era de vaca ou de porco. Um sabor muito bom (G.C.).

Comia capivara, tatu, queixado, cateto e anta. Eu lembro até, que eu gostava muito de comer anta, o pai matava, aí ele manteava e deixava no varal. Mamãe fazia pra nós, socava e depois fazia aquela paçoca de carne (L.G.).

Caça, porque pra nós aqui não tem mais caça. Vários tipos de caça... que eu gostava muito é o cateto e a carne do mateiro (A.H.).

Espaço Ameríndio, Porto Alegre, v. 8, n. 2, p. 87-107, jul./dez. 2014. 
Técnicas de "mantear, estender e deixar no varal" são apontadas como opção para a desidratação e conservação das carnes, para poder utilizá-las além de seu ciclo "natural".

O desmatamento foi apontado como um dos principais motivos da escassez da caça nos dias atuais, ficando difícil de encontrar os "bichos do mato", e, ainda, a proximidade com a cidade e a presença de estradas cortando a área.

Em tom de brincadeira, um entrevistado diz:

Os bichos já sabem até ler e escrever, estão muito velhacos. Hoje não existe mais, acabou. Os fazendeiros desbravaram, acabaram com as matas, os bichos se afastaram. Têm, mas muito pouquinho, ariscos (J.M.).

A necessidade da mata preservada e da presença dos animais se contrapõe com a atual degradação e limitação da terra. Os relatos falam da necessidade de andar na mata em um espaço amplo, sem fronteiras, não se restringindo ao espaço das roças e capoeiras, mas fazendo referência a um espaço para vagar e encontrar o que falta nos dias atuais.

Não estou muito bem. Sinto falta de andar na mata e de comer uma caça. E isso me faz muita falta hoje em dia (J.F.).

\section{Cozinha terena}

As entrevistas procuraram evidenciar as características da cozinha terena em sentido amplo, com a identificação do local de preparo e armazenamento, o próprio ato de cozinhar, os protagonistas desta cozinha, a pessoa com quem aprenderam a cozinhar e com que idade.

Ao conhecer as cozinhas terena observamos que se localiza fora dos domicílios, em locais reservados com especial destaque na construção. A maioria das cozinhas é construída de taquarussu e cobertas por sapé ou folhas de bacuri, mas encontramos também as cozinhas de alvenaria nas casas recebidas nos projetos sociais de moradia. Em muitas casas encontramos as duas cozinhas, sendo uma de 
alvenaria com o fogão a gás e a de taquarussu, anexa à casa, com o fogão a lenha.

No interior, observamos prateleiras de madeiras onde armazenam organizadamente as panelas de alumínios, cumbucas, travessas de barro, colheres de pau, escumadeiras e facas de cozinha. Em um canto da prateleira, encontramos pratos e colheres de sopa. Dificilmente verificamos garfos e facas de mesa. Observamos ainda vasilhas plásticas, muitas das vezes reutilizadas de alimentos industrializados como margarinas, maioneses e outras sendo denominadas "tapewares".

Acabou de comer, dá um jeito de guardar no tapeware (F.D.).

A cozinha terena é marcada pela presença de fumaça que vêm dos fogões a lenha sempre acesos. Sobre a chapa encontramos chaleira repleta de água fervente e, ainda, bule com chá. Na maioria das vezes, o chá é constituído de água com açúcar queimado. Em algumas casas encontramos na beira do fogão panelas com carne frita e mandioca cozida e, entre as brasas, algumas batatas assando.

Muitas casas tinham fogão a gás, porém com pouca utilização, devido a questões econômicas para manter disponível o botijão de gás durante todo período. Algumas mulheres chamam a atenção para os problemas da falta de dinheiro para comprar o gás de cozinha e a falta de árvores para a produção de lenha.

Observamos o preparo dos alimentos em função da disponibilidade de gêneros no domicílio, do número de comensais, das tarefas que irão desenvolver no dia e a existência de doentes na casa. As aparas e sobras são totalmente aproveitadas e, quando elas ocorrem, ficam disponíveis em cima do fogão durante o dia, especialmente para as crianças que buscam nos intervalos alguma coisa para comer. Sobras da refeição da noite eram armazenadas em vasilhas plásticas ou panelas dentro da geladeira para o consumo no dia seguinte. As famílias que não dispunham de geladeira preparavam a quantidade necessária para um dia de consumo, de forma que não houvesse desperdício dos alimentos.

Nos relatos obtidos, foi evidenciado que para armazenamento de carnes no momento em que ocorre abate de animais na área, fazem as 
mantas salgadas e distribuem em um varal de madeira específico para a secagem. As mantas de carne ficam expostas ao sol por um período calculado, a depender do prato que irão produzir, podendo ser armazenado por vários dias fora da geladeira e preparados de diversas formas, como a paçoca, onde a carne é frita e depois socada em um pilão com a farinha. Além desta preparação, muitas são as receitas que utilizam carnes desidratadas na culinária terena.

Segundo Woortmann (1985), a cozinha é um espaço de domínio feminino, sendo evidenciado no grupo pesquisado em área rural.

Entre as famílias terena estudadas, mães e as filhas são responsáveis pela cozinha, pelo preparo dos alimentos e pelos serviços da casa. Além dos serviços na casa, muitas delas dedicam-se à roça junto com os homens da família.

Buscamos, nas falas, identificar com quem e com quantos anos aprenderam a cozinhar, e os relatos foram:

Ah! Eu cozinhei desde pequena, meu pai tocava lavoura, e eu cozinhava. Ele trabalhou muito na fazenda e eu que era a cozinheira. Naquele tempo a gente socava arroz, fazia a comida para todo o pessoal. Eu comecei a cozinhar mais ou menos com uns dez ou onze anos (L.G.).

Sozinha, minha mãe não ensinava. Eu saia para trabalhar, quando era nova e ali aprendi a cozinhar (D.P.).

\section{Local e momento das refeições}

Durante todas as visitas, fomos recebidos em um espaço denominado "redondo", semelhante a uma varanda, coberto por sapé ou folha de bacuri, o piso sem revestimento (chão batido). Elas são estrategicamente localizadas, próximas à cozinha. Considera-se este local a parte mais importante do domicílio. É o local onde recebem as visitas e realizam as refeições. Geralmente possuem mesa, redes e bancos de madeira, ou apenas partes de troncos de árvores que servem de assentos. 
Sobre os horários que realizam as refeições e como elas ocorrem, os relatos indicam a preocupação em reunir a família.

Aqui eu faço o almoço pras as crianças às onze horas! Porque eles vão pra escola. [...] Mas comemos todos juntos. Comemos juntos, cada um no seu prato (M.A.).

Almoçamos juntos, meio-dia, no mais tardar meio-dia e quinze. O jantar sempre ao entardecer (G.C.).

Comemos todos reunidos, nós temos essa mania. Como fala o ditado, na hora de comer todo mundo junto (L.G.).

Apesar da presença da mesa, não costumam utilizá-la no momento das refeições. Servem os pratos buscando os alimentos no fogão e com os pratos nas mãos sentam-se em troncos de árvores e bancos distribuídos no "redondo". Na presença de visitas, oferecem os melhores assentos, e os membros da família se distribuem pelos bancos restantes ou se dirigem para a sombra das árvores próximas.

Sobre o número de refeições ao longo do dia e a indicação da composição da primeira refeição, as respostas foram:

Ah! Três vezes, porque aqui na aldeia é difícil pra comprar pão.

Aí, temos que fazer o arroz pela manhã, meu esposo come de manhã (D.P).

Meus filhos comem três vezes. Eles levantam a mãe já fez um arrozinho, frita um ovo e comem (G.C.).

Olha, aqui sempre nós comemos de manhã cedo, sete horas em diante, nós comemos. E onze horas, onze e meia até meio-dia nós almoçamos. Aí, seis horas, a janta (L.J.).

O almoço aqui é sempre 11 horas, está pronto o almoço, e a tarde procuramos jantar cedo, porque vamos para o culto (L.G.).

A permanência da equipe ao longo de vários dias nas comunidades possibilitou o registro das três refeições indicadas, sendo a primeira realizada no início da manhã, a segunda ao meio-dia e a terceira no início da noite. A primeira refeição era constituída basicamente de arroz 
e mandioca cozida. Em alguns domicílios foi observado o acréscimo de carne frita, ovo e chá mate. Nos domicílios com idosos, observamos o consumo de chimarrão (erva-mate regado com água quente) ao nascer do sol, antes da primeira refeição com alimentos sólidos.

Na cozinha, ou por aqui mesmo. Cada um pega um banco, serve lá. Pode ser aqui ou quando está muito calor debaixo do pé de manga. Aí vai todo mundo pra lá (M.A.).

Pra mim, toda a vida, eu fiz aqui, só de bermuda, sem camisa, chinelo, debaixo da arvore, eu como aqui fora. Sempre nós nos reunimos aqui (A.S.).

Sobre a ingestão de líquidos durante as refeições, muitos referiram o consumo de água, sendo que em uma das entrevistadas fez referência ao consumo de suco ou refrigerante:

Eu quase não tomo suco, mas as crianças pedem suco bem geladinho, guaraná ou coca-cola no almoço (D.P.).

Sobre a comida do homem e da mulher, ouvimos:

Acho que não, o mesmo que eu como ele come (D.P.).

Não, estando com saúde, não. Porque se você estiver doente já tem diferença, é outra coisa (A.S.).

Se a mulher estiver de dieta tem que comer uma comida diferente do homem (A.S.).

Os relatos demonstraram que as mudanças são em situações específicas como doença, gestação, puerpério, no período de amamentação e na velhice. Questões que serão abordadas nos tópicos a seguir.

\section{O comer e a doença}

Com o intuito de avaliar práticas alimentares relacionadas à saúde-doença, buscamos identificar a presença de regras alimentares 
específicas. Foram apresentados relatos holísticos sobre os determinantes que podem levar a uma doença.

O povo preocupa muito com crianças e os jovens, devido aos espaços, não temos mais espaços suficientes para trabalhar e extrair, nem morada temos mais... De repente vai contribuindo com a possibilidade de se transformar em doença. A pressão alta devido o calor... e as coisas que ingerimos, isso tudo contribuiu. Em relação à doença, pode ser pela quebra de regras com a alimentação. Com o crescimento da população, hoje tem mais aproximação com a cidade, vamos mais para a cidade, adquirimos os hábitos dos brancos (B.J.).

Agora essa geração que está vindo, quanto mais infiltrado nos hábitos purutuy... parece que é bom. Porém, traz despreparo para o corpo, para combater das doenças que iriam vir. Se pudessem preservar aquelas comidas que são originais, teria mais facilidade do nosso corpo combater as doenças (J.R.).

As narrativas evidenciam o crescimento demográfico na região, a escassez de terra para o viver terena, as mudanças climáticas e a significativa influência do meio urbano nas comunidades indígenas, levando alterações na saúde. Para os entrevistados, as crescentes alterações implicam no aparecimento de doenças que, em outras épocas, não eram vivenciadas nas comunidades.

Isto não existia. Eu sempre comento que na aldeia indígena não aconteciam estes tipos de doenças, como: derrame, pressão alta, diabetes... Essas coisas não eram vistas falando em nossa comunidade, nunca existiu isto aqui. $E$ hoje, vivenciamos em nossa comunidade. Muita gente diabético... a maioria sofre de pressão alta, uma coisa que não existia no passado aqui (B.J.).

Os relatos reforçam a dicotomia passado/presente, com destaque para doenças que desconheciam, mas que agora é frequente, em função dos novos riscos. Sobre a presença de regras com indicação de restrições alimentares encontramos:

Troca... aí vem um ensopado de macarrão, de arroz, sopinha de frango. Este é o cardápio quando a pessoa 
não está em perfeita condição de saúde. ... tem doença que tira o apetite da pessoa, por exemplo, a gripe mesmo tira o apetite e pede um caldo. Conforme a necessidade (G.C.).

Aqui, o que evitamos é o frango. No hospital, a pessoa está com febre, e vem uma sopinha de frango ou ovo frito... Aqui, se comer em certos lugares, é um porrete, ele vai pro caixão direto... Eu não sei por que no hospital eles comem (G.C.).

Desta forma, o consumo destes produtos contribuiria para o agravamento das doenças, aumentando a infecção e a febre. Inúmeros estudos etnográficos abordam a questão dos alimentos que são caracterizados como quentes e frios. No estudo de Canesqui (2007), ela revela que existem diferenças no conceito dos alimentos considerados quentes ou frios em determinadas regiões do Brasil, onde para uma região o que é considerado quente para outra é frio e vice-versa.

Um dos entrevistados havia tido alta hospitalar recentemente, após ter sido submetido a uma cirurgia. Seu relato contextualiza as orientações recebidas do médico e o que entendia como possível e importante a ser seguido.

Depois da cirurgia eu passei a acompanhar a orientação do médico. [...] Suspendeu várias alimentações, e outras que a gente nem comia. Não tinha vontade de comer também... Eu comia uma sopa de arroz, um caldinho (B.J.).

A doença sem dúvida altera todo o regime alimentar. Remem (1993) salienta que com o surgimento da doença haverá uma interrupção dos costumes, o que contribui categoricamente com as mudanças nas práticas alimentares.

Nas narrativas sobre comidas para curar, prevenir e proteger de doenças, identificamos alimentos utilizados com amplas finalidades.

O alho é bom pras doenças do coração, é um remédio fresco. Também é bom para friagem, espirro e dor de cabeça, você deve cheirar. Pode ser usado na comida. No sistema do índio, você mastiga o alho cru, e pode ir ao mato para não pegar berne, e ainda a cobra sai da frente. $O$ alho é contra o mal, o mal que está na frente (A.S.). 
Eu sei do arroz, a casca do arroz é uma vitamina muito boa. Quando uma pessoa está sem apetite, você pega a casca e torra até ficar uma poira [pó], em cada refeição coloque uma pitada. Não vai daí três dias, a pessoa esta comendo até ferro se achar. Ele é um produto do mesmo alimento, é um santo remédio (G.C.).

Segundo resultados de estudos biomédicos disponíveis na $V I$ Diretriz de Hipertensão Arterial (2010), o alho, cujo principal componente ativo é a alicina, tem ação metabólica, podendo atuar na coagulação, aumentando o tempo de sangramento e promovendo discreta redução de pressão arterial.

$\mathrm{Na}$ busca das recomendações específicas para diferentes estágios da vida, identificamos relatos com indicações para o período puerperal.

Segundo Carraro (1997), na linguagem popular o puerpério é conhecido como o período do resguardo, pós-parto, dieta, quarentena, durando cerca de quarenta dias e é repleto de grande significação cultural.

Pode comer peixe, ave, capivara, mateiro e tatu. O tatu peba é muito bom. Pelo menos um pedacinho, a carne é medicinal como meu avô falava (E.).

A nossa comida era só fubá, "farinha de fubá", fazia aquele mingauzinho. Mamãe matava frango para nós. Durante sete dias não podia comer nada, somente o fubá. Hoje em dia não, você vai ao médico e no outro dia já está comendo comida. Não tem dieta mais (L.G.).

Comer uma comida leve (A.S.).

O frango criado pela própria família foi citado, sendo o mais indicado para o consumo das puérperas, crianças, idosos e portadores de patologias. As frutas não foram mencionadas como restrições. Segundo os entrevistados, a comida leve deve conter:

Uma batata, um pouco de macarrão, um franguinho novo. Faz uma sopinha leve, com pouco sal pra mulher gestante ou conforme a doença também (A.S.).

O frango cozido ou frito, misturado com o fubá de milho, todas as vezes que ganhávamos neném (L.G.). 
As regras deste período vão além das recomendações e restrições alimentares. Relacionam-se, também, a outras práticas que as mulheres neste período deveriam observar.

A mulher, quando ganhava neném, ficava sete dias dentro de casa, sem tomar vento nenhum. Eu tomava chá de capim cidreira. A mãe fazia para nós muito chá de mate com carvão, para aumentar leite do peito. Ela queimava o açúcar e fazia o chá com carvão (L.G.).

Para Castro (apud BAIÃO e DESLANDES, 2006), o puerpério dispõe de um período de restrição alimentar, relatando que, de modo geral, a parturiente precisava esperar pelo menos quarenta dias para comer frutas e ainda só uma carne era permitida, a carne de galinha servida com arroz.

Um dos entrevistados revelou que a carne de porco não é indicada para mulheres que estão no puerpério ou doentes com infecções.

Tem muitas comidas reimosas como a carne de porco, que não pode comer, que é quente. Tem que ser uma coisa mais simples, que não tem banha (A.S.).

Segundo Canesqui (2007), a "reima" não é uma categoria classificatória amplamente disseminada, sendo observada em discursos dos pescadores, caboclos, indígenas ou agricultores pertencentes às regiões Norte, Centro-Oeste e Nordeste do país. Por sua vez, constitui uma forma de classificar o grau de segurança dos animais selvagens e domésticos para o consumo (MORAN, 1974 apud SILVA, 2007).

\section{Conclusões}

O presente estudo identificou a cozinha terena, mudanças na composição da dieta em situações específicas vivenciadas por mulheres no puerpério e recomendações gerais em situações de doença.

Os relatos evidenciaram significativas mudanças nas práticas alimentares, com destaque para as mudanças ocorridas na obtenção e plantio dos próprios alimentos, a introdução de alimentos 
industrializados e as preocupações com os resultados oriundos dos novos hábitos.

A proximidade com área urbana e os meios de comunicação, especialmente o rádio e a televisão, levam a propaganda dos produtos industrializados de forma maciça aos lares terena.

A limitação da área disponível, a degradação ambiental e a presença de alimentos fornecidos na cesta básica foram indicadas como elementos que contribuem para alterações da dieta terena.

A permanência da cozinha de taquarussu, o fogão a lenha, a conservação das carnes pela desidratação, os alimentos disponíveis no fogão, o local das refeições, a família reunida, os utensílios e as receitas transmitidas oralmente são elementos repletos de valores simbólicos da cultura terena.

Novos estudos são necessários para aprofundamento de elementos aqui identificados e abordados como pequenos fragmentos da realidade, necessitando de maior discussão teórica sobre a rica experiência terena em contexto de mudança.

\section{Referências bibliográficas}

BAIÃO, Mirian Ribeiro; DESLANDES, Suely Ferreira. Alimentação na gestação e puerpério. Rev. Nutr., Campinas, v. 2, n. 19, p. 245-253, mar./abr. 2006.

BUNCHAFT, Alexandra Flávio; GONDIM, Sônia Maria Guedes. Grupos focais na investigação qualitativa da identidade organizacional: exemplo de aplicação. Revista Estudos de Psicologia, Campinas, v. 21, n. 2, p. 63-77, 2004.

CANESQUI, Ana Maria. Comentários sobre os estudos antropológicos da alimentação. In: CANESQUI, Ana Maria; GARCIA, Rosa Wanda Diez (Org.). Antropologia e nutrição: um diálogo possível. Rio de Janeiro: Editora FIOCRUZ, 2005. p. 23-47.

A qualidade dos alimentos: análise de algumas categorias da dietética popular. Rev. Nutr., Campinas, v. 20, n. 2, p. 203-216, mar./abr., 2007.

CARRARO, Telma Elisa. A mulher no período puerperal: uma visão possível. Texto Contexto Enf., Florianópolis, v. 6, n. 1, p. 84-91, 1997.

DAMATTA, Roberto. O que faz o Brasil, Brasil? Rio de Janeiro: Rocco, 1986. 
DOMINGUEZ, Bruno. Agrotóxicos: proteção para quem? Radis, Rio de Janeiro, n. 95, p. 11-15, jul. 2010.

FISCHLER, Claude. El (h)omnívoro: el gusto, la cocina y el cuerpo. Barcelona: Editorial Anagrama, 1995.

GARCIA, Rosa W. Diez. Representações sociais da comida no meio urbano: um estudo no centro da cidade de São Paulo. 1993. 132 f. Dissertação (Mestrado em Psicologia Social) - Universidade de São Paulo, [1993].

REMEM, Rachel Naomi. Uma maneira saudável de ter uma doença. In: $\mathbf{O}$ paciente como ser humano. São Paulo: Summus, 1993. p. 99-127.

ROMANELLI. Geraldo. O significado da alimentação na família: uma visão antropológica. Medicina, Ribeirão Preto, n. 39, v. 3, p. 333-339, jul./set. 2006.

SILVA, Andréa Leme. Comida de gente: preferências e tabus alimentares entre os ribeirinhos do Médio Rio Negro (Amazonas, Brasil). Revista de Antropologia, São Paulo, v. 50, n. 1, p. 125-179, 2007.

SILVA, Fernando Altenfelder. Mudança cultural dos Terena. Revista do Museu Paulista, São Paulo, v. 3, 1949.

SOCIEDADE BRASILEIRA DE HIPERTENSÃO. VI Diretriz de Hipertensão Arterial. v. 13, n. 1, 2010.

SLOAN, Donald. Gastronomia, restaurantes e comportamento do consumidor. São Paulo: Manole, 2005.

ZUIN, Luis Fernando Soares; ZUIN, Poliana Bruno. Alimentação é cultura: aspectos históricos culturais que envolvem a alimentação e o ato de se alimentar e o ato de se alimentar. Nutrire, São Paulo, v. 34, n. 1, p. 225-241, abr. 2009.

WOORTMANN, Klaas. A comida, a família e a construção do gênero feminino. Brasília: UnB, 1985. (Série Antropologia, 50). 